Article

\title{
Revitalising South African City Centres Through ICT
}

\author{
Dillip Kumar Das
}

Sustainable Transportation Research Group, School of Engineering, Howard College, University of KwaZulu-Natal, South Africa; E-Mails: dasd@ukzn.ac.za, dkd1267@gmail.com

Submitted: 18 April 2021 | Accepted: 14 July 2021 | Published: 17 November 2021

\begin{abstract}
The majority of South African city centres are in a state of degeneration and need revitalising. The factors that contributed to the degeneration and how the integration of information and communications technology (ICT) can be used to revitalise them were examined in three South African city centres. The research was grounded in place theory. A survey method, including the Delphi technique, followed by factor analysis, and ordinal regression modelling was used to collect and analyse data. The findings indicated that enhancing accessibility and safety, social and community involvement, human experience, built-up environment, and vibrancy were the five major components which needed reinforcing to revitalise the city centres. However, ICT-linked strategies, including networking the areas with free Wi-Fi hotspots, creating places in which to congregate, providing digital screens, and installing cameras and remote monitoring, are expected to attract people and to facilitate accessing real-time information about different events, marketing, branding, and creating a unique image. Also, the use of ICT will assist in reducing criminal activities and dispel the fear of crime. The combined effect is likely to encourage people and businesses to return the city centres, making these areas vibrant and accessible.
\end{abstract}

\section{Keywords}

Bloemfontein; city centres; degeneration; ICT; place theory; Port Elizabeth; Pretoria; revitalisation; South Africa

\section{Issue}

This article is part of the issue "Towards Digital Urban Regeneration: Embedding Digital Technologies Into Urban Renewal Processes and Development" edited by Dalit Shach-Pinsly (Technion-Israel Institute of Technology, Israel).

(C) 2021 by the author; licensee Cogitatio (Lisbon, Portugal). This article is licensed under a Creative Commons Attribution 4.0 International License (CC BY).

\section{Introduction}

City centres play a crucial role in the socio-economic wellbeing of a city. Despite the decentralisation process, which has been experienced in many cities around the world, city centres are often found to be the source of services such as commerce, administration, transportation, etc. (Alexander et al., 2020; Jones \& Livingstone, 2018). City centres offer prime locations for housing and residences, as well as recreational, cultural, and tourist activities. Moreover, within a compacted area, city centres encourage diversity, enable community and social interaction, and promote communication (Das, 2016; Powe \& Hart, 2008; Steyn, 2012). Morphologically, according to Swiss-French architect Le Corbusier, the structure of city centres is observed to be enormous, adaptable, active, sharp, intense, and dominant, within which a richly varied, refined vista of buildings, organised in an asym- metrical manner, generates a powerful rhythm (Laua \& Lib, 2019).

However, in various countries, city centres have been gradually losing their importance (Powe \& Hart, 2008; Wrigley \& Lambiri, 2014). New centres of activities have emerged and, in the face of this competition, the bustling hearts of cities have increasingly been marginalised (Alexander et al., 2020; Jones \& Livingstone, 2018). Some of the city centres in many developing countries have continued to exist simply for their historical importance or as tourist attractions.

Similarly, in South Africa, city centres are an integral part of most urban areas. These city centres were once the nerve centres of major commercial, residential, administrative, cultural, and recreational activities. The major public transport terminals are located close to the city centres. These areas also contain several cultural heritage and architectural monuments and other 
tourist and recreational attractions. However, in recent years, it has been observed that several of the commercial and administrative elements have been moved out of the city centres. The reasons could be attributed to a range of factors that include overall degeneration of the area as a result of a decline in infrastructural facilities, poor management and maintenance, and a reduction in the number of commuting people, leading to a decline in economic activities and the emergence and availability of more affordable, modern built-up infrastructure and activity centres in other sub-urban areas. Also, the perception has been that city centres have been overrun by criminal activities. This is alleged to have happened because of poor control over the occupancy of dilapidated or abandoned buildings, lack of adequate attention to required infrastructure, such as lighting and security measures, as well as poverty, economic inequality, etc. Consequently, people do not want to visit city centres out of fear. Furthermore, the housing conditions have deteriorated. The value of the real estate, specifically in the housing sector, has declined.

In South Africa, a spatial development framework for the sustainable development of cities has been adopted, in which the main focus is on social integration and environmental considerations (Todes, 2011). Accordingly, efforts have been made to undertake urban renewal projects in some of the city centres to reduce segregation and make them more inclusive and vibrant. However, the degeneration of city centres continues, raising the question of why these areas degenerate and how this can be addressed.

Information and Communications Technology (ICT) and various products driven by the Internet of Things (IoT) have become an integral part of daily life. Smart technology has engendered functional and spatial changes in various places, including city centres, and brought about behavioural changes among people. This influence is likely to continue with further technological advancements (Alghamdi \& Al-Harigi, 2015; Das, 2016). Evidence from cities around the world-e.g., New York, Toronto, London, and Vienna-suggests that ICT can play a very important role in reviving the image of city centres. Consequently, it has been argued that ICT should be considered as an integral part of re-developing or revitalising city centres in developing countries.

Therefore, how the integration of ICT in city centres can be used to revitalise the urban areas of South Africa was explored in this study, within the context of three major cities. Specifically, the current state of city centres, the presence and influence of ICT, and the role of ICT in the revitalisation process were assessed, and strategies that would enable the revitalisation of the city centres were examined. For this purpose, the following research questions were addressed:

1. What is the current socio-economic, spatial, visual, and image-building status of the city centres in South Africa?
2. What is the current status of ICT in the city centres?

3. What roles can ICT play in revitalising the city centres?

4. What strategic interventions are needed to revitalise the city centres?

\section{Literature Review}

The research for this study was grounded in place theory and the implications of ICT in placemaking.

\subsection{Theoretical Frameworks for Urban Renewal and Redevelopment}

Urban renewal is considered to be one of the most effective approaches to improving the spatial and environmental quality of a place (Zheng et al., 2014). The approach has been adopted to rectify the urban decay problem, meet socio-economic objectives (Lee \& Chan, 2008), enhance existing social networks, improve the inclusion of vulnerable groups, and change adverse impacts on the living environment (Zheng et al., 2014). This approach creates an opportunity to re-use land, improve the land value and physical, spatial, and environmental quality of a place, create a unique place brand image, and it also contributes to the sustainability of cities (Wang et al., 2014; Zheng et al., 2014).

Several theoretical frameworks have been adopted for urban renewal or re-development processes, including sustainable development theory, smart growth theory, new urbanism theory, organic renewal theory, and place theory. Since this study was premised on place theory, this has been discussed separately in Section 2.2.

Furthermore, arguments for giving attention to the interaction among urban, architectural, technological, economic, socio-cultural, environmental, and politicaladministrative dynamics that evolve within a specific urban area have emerged (Battisti et al., 2019; Corburn \& Cohen, 2012). Also, greater integration of people in the urban re-development or renewal process should be emphasised (Battisti et al., 2019).

\subsection{Place Theory in Placemaking}

Place theory is concerned with human-world relations through experience (Laua \& Lib, 2019; Pred, 1984). Pred (1984, p. 279) defined a place by its functions, which occur ceaselessly, and its contribution to history in a particular context through the creation of a physical setting. A place is not simply what is seen on the land, a setting, or a location for human activities. Rather, "place" refers to the functions and contributions made to history, culture, society, and economy by the use of a physical setting. Furthermore, a sense of place implies the ability to recognise different identities of a place (Ralph, 1976, p. 63). However, the location or spatial and physical attributes are insufficient to create a sense of place. So, according 
to Castree (2009), human experiences provide meaning to a place. In other words, not only one's perception but also one's feelings about a place constitute a sense of place. Therefore, "place" and "sense of place" are intertwined in the creation of places. Moreover, technological changes, which fundamentally affect the attributes of a place, have added another dimension to the development of a place (Ralph, 2016). Both tangible attributes, such as the physical setting and infrastructure, and intangible features, such as distinctive experience, together with the role of technology, create the uniqueness of a place (Laua \& Lib, 2019; Ralph, 2016; Richards \& Palmer, 2010).

In place theory, it is professed that a place should be developed in such a way that it not only has tangible aspects but also reflects intangible experiences, such as people's perceptions and feelings about the place and the community (Castree, 2009; Laua \& Lib, 2019). In addition to this, the incorporation of advanced digital technology, such as ICT, should be an integral part of placemaking.

In an urban development context, a central area or city centre can be considered as a place. While revitalising the central area of a city, in addition to the creation/upliftment of a social setting through physical interventions that incorporate the intrinsic value associated with the setting (Laua \& Lib, 2019; Strydom et al., 2018), the transformation must also be used as an instrument for empowerment. In other words, community empowerment, engagement of community, and community practice should be taken into consideration in the urban regeneration or revitalisation process (Al-Kodmany \& Ali, 2012; Strydom et al., 2018). Furthermore, ICT should be employed as an enabler not only for the physical and spatial transformation, but also for the creation of a sense of place through empowerment and enriching human experience.

\subsection{The Role of ICT in Placemaking}

ICT has become indispensable in many spheres of public activity and, consequently, has transformed society and cities as well (Fernandez-Maldonado, 2012). ICT is considered to be a desirable tool for social and economic connectivity and urban efficiency (Castells, 1996; Fernandez-Maldonado, 2012; Storper, 2010). Moreover, it has been argued that innovative uses of ICT can assist in achieving urban sustainability by improving the efficient use of energy and water, decreasing carbon emissions and waste, and enabling public participation in decisionmaking about various urban developments (FernandezMaldonado, 2012; Mitchell \& Casalegno, 2008).

Arguments stating that the outstanding informational and networking capacities that ICT presents should be utilised to bring about positive effects in economic and social development, and improvements in spatial development, quality of life and public participation have emerged. In this process, the use of ICT will make cities and human settlements inclusive, safe, resilient, and sustainable (Nkosi, 2018). Furthermore, it has been argued that ICT can be deployed to contribute to creating a unique image of a place as well as shape spatial development (Das, 2016). However, there must be adequate access to ICT infrastructure and connectivity for people to benefit from ICT networks (Fernandez-Maldonado, 2012).

In the context of urban regeneration or revitalisation, specifically at the micro-level of central areas, it has been argued that ICT plays a critical role. For instance, ICT can be used to influence both the agglomeration and dispersion of central functions such as trade, commerce, entertainment, and social and civic activities (Alghamdi \& Al-Harigi, 2015; Castells, 1996; Pratt, 2008). Moreover, locating global economic activities with the existence of both agglomeration and dispersion and socio-economic diversity would improve the image of a place in a city, including the central area (Little, 2013; McDonald \& Swinney, 2019; Sassen, 1996). For instance, ICT plays a crucial role in the retail commercial sector. If strengthened in the central areas of cities, the ICT infrastructure can be used to assist in the effective functioning of the retail environment, supply chain, and customer service management, as well linking various aspects of trade and commerce, such as financial and inventory databases. It has been contended also that ICT can be used as a tool by marketing professionals to analyse the market. For instance, through its various services, such as providing free $\mathrm{Wi}-\mathrm{Fi}$ in public places or coffee shops, and providing services through mobile phones, ICT can be used to attract people and activities to the central areas, which is an important aspect in revitalising the central areas (De Filippi et al., 2020; Jeong et al., 2010). Similarly, the use of ICT would support the designing of spaces by urban planners, architects, and designers (Lepy, 2008). For example, planners, architects, and designers can use ICT to understand the available space better, examine the land use, and improve space utilisation and management of the central areas.

Furthermore, it has been argued from a planning perspective that ICT can be used to enhance people's participation in planning and decision-making and to engage them in co-design and co-production of spaces and activities (Kwon, 2009). In this context, according to De Filippi and Balbo (2011), the use of ICT enables multi-modal, synchronous, or selective representation. Specifically, the use of ICT could permit marginal citizens to participate in the development or revitalisation processes by enhancing their awareness, encouraging interaction of individuals with diverse communities beyond time and space limits, and contribute to increasing the general level of democracy and equity. Moreover, it can invoke on-demand or real-time actions by different responsible authorities. For example, people can report issues related to environmental degradation and the incidence of crimes directly to the concerned authorities by using ICT applications and services, which 
can prompt the authorities to take action as needed (Kingston et al., 2005).

Although the role and impact of ICT on a regional, national, or city scale have been studied to a certain extent (Das, 2016; Mitchell \& Casalegno, 2008; van den Berg \& van Winden, 2002), studies in the context of central areas or on a micro-scale in the cities in developing countries have been scarce. Thus, since it has been argued that ICT plays a significant role in placemaking, there was a need to examine how ICT can be used to influence the development of city centres or assist in their revitalisation.

\section{Study Context and Research Methods}

A quantitative research method was adopted, using a survey for data collection, and both descriptive and inferential statistical methods were used for analysis and modelling.

\subsection{Study Context}

Three major cities of South Africa-Bloemfontein, Pretoria, and Port Elizabeth-were selected as the study context. These cities were selected based on a set of criteria such as heterogeneity in geographical location and spatial, structural, and functional homogeneity. These cities are located in three separate regions of the country: Pretoria in the north, Port Elizabeth (renamed as Gqeberha) in the southeast, and Bloemfontein in the centre, providing heterogeneous geographical representation. Each city has a designated central business district in which several urban functions are performed, and each city has its image. The physical form and structure of the city centres were observed to be more or less similar. These central areas enclose predominantly mixed land use, with functions including trade and commerce, administration, transportation, culture, and recreation. These central areas convey distinct images and have regional and national importance. For example, they are the major cities of each region and two of these are capital cities. While Bloemfontein is the provincial capital of the Free State, Pretoria is the administrative capital of the country. Port Elizabeth is the largest city of the Eastern Cape province. The historic, tourist, and architectural elements in these spaces offer structural homogeneity. These city centres offer similar functions that are predominantly commercial, followed by administrative and recreational functions. However, it has been argued that these cities are degenerating and that various functions are being moved out for one or more of the reasons discussed previously. Also, spatial, social, and economic activities are declining (see Section 1). So, while there is physical, structural, and functional homogeneity, the central areas of these cities represent geographical heterogeneity. Consequently, these cities were observed to be representative of similar, medium-sized cities in the country.
Therefore, they were considered to be ideal candidates for this investigation.

\subsection{Data Collection and Analysis}

Two types of surveys were conducted to collect data. Firstly, a survey among the stakeholders in the city centres was conducted to examine the factors and attributes that would be essential for revitalisation. The stakeholders included people employed in the city centres, local visitors, residents in the area, and tourists. The survey sample included 840 respondents. The sample sizes accessed in each of the selected cities varied between 260 and 350, but valid responses ranging between 242 and 311 were returned. Table 1 shows a summary of the profile of the survey's respondents. The sample size for each city was found to be adequate at a confidence level of $95 \%$, with a confidence interval ranging between $5.56 \%$ and $6.3 \%$, and a worst-case percentage of $50 \%$. However, overall, the sample size was found to be more than adequate $(>384$ ) for a confidence level of $95 \%$, with a variance of $5 \%$, and a worst-case percentage of $50 \%$. Based on the willingness and availability of the respondents, random sampling and a semi-structured interviewing process were used. Care was taken to avoid bias towards any race, gender, or age of the respondents, or skewness towards one group of respondents. For this purpose, in addition to the use of random sampling methods, different sub-groups of respondents, such as people belonging to different races, age groups, and gender were selected according to a proportional distribution corresponding to their population size.

In addition, a Delphi survey was conducted among 31 experts and professionals to understand the various ICT-linked strategies and policy interventions that would be essential to revitalisation (Liggett et al., 2011). The Delphi survey was deemed to be suitable because it offers a structured group communication process, which enables a group of experts to deal with a complex problem effectively (Hsu \& Sandford, 2007). Furthermore, compared with other alternative methods, such as multicriteria decision-making, nominal group technique, and brainstorming, Delphi involves a reasonable number of isolated and anonymous respondents to guide group opinions towards a final decision or to answer questions through triangulation of subjective group opinions, according to the analytical techniques and experience of the researcher. It is also a multi-stage process, in which each stage builds on the previous one, which leads to convergence of opinions. Moreover, the Delphi method is observed to be substantially more accurate than either individual experts, traditional groups, or statistical groups in which judgements of non-interacting individuals are aggregated (Rowe \& Wright, 2001). On the other hand, multi-criteria decision-making methods, (e.g., analytical hierarchy process) are data intensive. Similarly, nominal group technique and brainstorming are based on a relatively smaller size of groups in which members 
Table 1. Summary of the profile of respondents.

\begin{tabular}{lcccc}
\hline Respondents' Attributes & Bloemfontein & Pretoria & Port Elizabeth & Total \\
\hline Total of questionnaires administered & 260 & 300 & 350 & 910 \\
Total of valid responses received & $242(93.7 \%)$ & $287(95.5 \%)$ & $311(88.9 \%)$ & $840(92.3 \%)$ \\
Category of the respondents & & & & \\
$\quad$ Local residents & $216(89.3 \%)$ & $256(89.2 \%)$ & $282(90.7 \%)$ & $754(89.8 \%)$ \\
$\quad$ Visitors & $26(10.7 \%)$ & $31(10.8 \%)$ & $29(9.3 \%)$ & $86(10.2 \%)$ \\
Gender & & & & \\
Male & & & & \\
Female & $141(58.3 \%)$ & $176(61.3 \%)$ & $192(61.7 \%)$ & $509(60.6 \%)$ \\
Race & $101(41.7 \%)$ & $111(38.7 \%)$ & $119(38.3 \%)$ & $331(39.4 \%)$ \\
White & & & & \\
African & $34(14.0 \%)$ & $31(10.8 \%)$ & $38(12.2 \%)$ & $103(12.3 \%)$ \\
Coloured & $186(76.9 \%)$ & $227(79.1 \%)$ & $235(75.6 \%)$ & $648(77.1 \%)$ \\
Other & $14(5.8 \%)$ & $18(6.3 \%)$ & $21(6.8 \%)$ & $53(6.3 \%)$ \\
Age & $8(3.3 \%)$ & $11(3.8 \%)$ & $17(5.4 \%)$ & $36(4.3 \%)$ \\
18-25 & & & $86(27.7 \%)$ & $228(27.1 \%)$ \\
$26-40$ & $64(26.4 \%)$ & $78(27.2 \%)$ & $93(31.8 \%)$ & $274(32.7 \%)$ \\
$41-60$ & $82(33.9 \%)$ & $93(32.4 \%)$ & $99(29.3 \%)$ & $248(29.5 \%)$ \\
$\geq 61$ & $73(30.2 \%)$ & $84(29.3 \%)$ & $91(29.3 \%)$ & $90(10.7 \%)$ \\
\hline
\end{tabular}

might be known to each other and decisions are based on voting or consensus. Since not much structured statistical data was available and the study relied on expert opinion for developing strategic interventions through a rigorous analytical process, the Delphi technique was found to be more appropriate and was thus used.

The participants included four urban planning and design professionals, three architects, four civil engineers, six academics from the field of architecture and urban planning, three urban development executives (officers in charge of implementation), four entrepreneurs, two individuals engaged in imagebuilding and branding, two sociologists, and three ICT experts. The experts were selected according to their relevant expertise, experience, and engagement in city development. The focus of the discussions was on ICT-linked strategies and how they could enable the revitalisation of the city centres. The responses of the stakeholders were measured using a five-point Likert scale with the values being: 1. Very Low, 2. Low, 3. Fair, 4. High, and 5. Very High.

Both descriptive statistics and inferential statistics, including a perception index (mean Likert scale scoreperception index $[\mathrm{PI}]$ ), standard deviation (SD), and z-probability were used to examine the accessibility and use of ICT in different activities in the city centres. Factor analyses, by means of principal component analysis (PCA) with varimax rotation, were used to carry out exploratory analysis of the identified components and attributes required for revitalisation. PCA is one of the most widely used tools for data analysis and is useful for a variety of situations and data types. PCA can be used to simplify the complexity in high-dimensional data without compromising the trends and patterns. One of the major advantages of this method is that it can be used to assist in reducing the dimensionality of large data sets and to increase interpretability with minimum information loss. Moreover, PCA displays similar accuracy on the validation set with various other methods such as baseline, missing values ratio, low variance filter, high correlation filter, random forest/ensemble trees, etc. Although it offers relatively less accuracy than backward feature elimination, missing values ratio and forward feature construction, and missing values ratio methods, it is much less time-consuming. PCA also helps in ranking and reduces the redundant and noisy features (Jolliffe \& Cadima, 2016; Velliangiri et al., 2019). In the current study, since the data collected were on an ordinal scale and it was necessary to group various attributes under a set of limited and important components to examine the factors that influence the vitality of central city areas, PCA was found to be suitable.

Kaiser-Meyer-Olkin (KMO) and Bartlett's tests were conducted, and communalities were calculated to check the adequacy of the sample size and the validity and robustness of the model. A scree plot was used to extract and retain the principal components. Varimax rotation was conducted to interpret the components and various attributes under the components.

Ordinal regression modelling was done to examine the relative influence of the ICT-linked strategies, while constructing the ordinal regression model, goodness of fit, likelihood test, and test of parallel lines were 
conducted to check the veracity of the model (Williams \& Quiroz, 2020).

\section{Results and Discussion}

Four aspects-namely accessibility of ICT in the city centres, use of ICT in different activities, various attributes of city centres, and the strategic measures-were analysed as presented in the following subsections.

\subsection{Accessibility of ICT in the City Centres}

Analysing the accessibility of ICT is essential to understand the readiness and challenges of a place so that ICT can be used to influence various activities significantly and to augment them. Table 2 shows the ICT accessibility in the city centres as perceived by the respondents. Accessibility was significant in terms of both broadband and Wi-Fi internet connectivity. Similarly, connectivity by GPS was significant in these areas. However, free Wi-Fi hotspots were available to a certain extent and people could access free $\mathrm{Wi}-\mathrm{Fi}$ in a limited number of places in the central areas. Also, CCTV cameras were available to regulate and monitor traffic and other socio-economic activities at limited locations. However, the presence of digital messages and signage, intelligent transport systems and sensors for traffic control and parking, CCTV cameras with internet connectivity for real-time remote monitoring, and other loT applications were meagre. This suggested that, although the city centres had ICT or digital connectivity, the accessibility needed significant augmentation. Evidence from literature suggested that ICT plays a crucial role in the regeneration or revitalisation of areas, for instance, through enhancing interaction among people and attracting small businesses (De Filippi \& Balbo, 2011; Kwon, 2009). Therefore, to revitalise the city centres, the various attributes of ICT, as observed above, should be augmented to improve its accessibility.

\subsection{Use of ICT in Different Activities in the City Centres}

The use of ICT in different activities is shown below in Table 3, which indicates the contribution of ICT to different aspects related to the functioning of the city centres in the existing situation. The use of ICT or its contribution has been categorised under 11 distinct and broad categories. According to the PI, the use of ICT was significant for normal socio-economic activities that included office, commercial, and recreational activities. People used ICT for e-commerce to a certain extent. Similarly, people accessed real-time information for various reasons (for example, transportation, social and economic activities, and events or sporting activities). Advertisement of socio-cultural activities and promotion of tourism were conducted to some extent. However, ICT was not generally used for e-governance/public participation, monitoring of crime, real-time monitoring of different social activities and public places, or real-time display of information. This indicated that, although people used ICT for certain socio-economic activities and could access ICT through their private mobile devices, and the city authorities used ICT for certain promotional and advertising purposes, ICT was not used extensively in essential activities, such as monitoring crimes, public participation in governance systems, and displaying real-time information in public places, which could be a barrier to people visiting and participating in developmental and governance activities in the city centres. Furthermore, the overall role of ICT was found to be not significant statistically, but respondents perceived that it could contribute significantly to the creation of vibrant city centres. However, it has been argued that appropriate and adequate ICT infrastructure, if created, would facilitate various activities, empower people, improve human experience and interaction in the central areas, and, thus, help in their revitalisation (De Filippi \& Balbo, 2011; Kwon, 2009). So, in the context of South African

Table 2. Accessibility of ICT in the city centres.

\begin{tabular}{|c|c|c|c|c|c|}
\hline Attributes & $\mathrm{PI}$ & SD & z-score & z-probability & $\mathrm{p}$-values \\
\hline Availability of internet by broad band & 4.19 & 0.68 & 1.75 & 0.959 & 0.00 \\
\hline Availability of Wi-Fi & 4.05 & 0.63 & 1.67 & 0.952 & 0.00 \\
\hline Free Wi-Fi hotspots & 3.25 & 0.59 & 0.41 & 0.659 & 0.00 \\
\hline Message and signage boards & 2.60 & 0.58 & -0.67 & 0.251 & $0.999 *$ \\
\hline GPS & 4.16 & 0.65 & 1.78 & 0.962 & 0.00 \\
\hline $\begin{array}{l}\text { Use of intelligent transport systems and sensors } \\
\text { for traffic control and parking }\end{array}$ & 2.59 & 0.72 & -0.57 & 0.284 & 0.999* \\
\hline CCTV cameras & 3.62 & 0.60 & 1.04 & 0.850 & 0.000 \\
\hline CCTV cameras connected with Wi-Fi & 2.02 & 0.64 & -1.51 & 0.065 & 0.999* \\
\hline Other loT apps & 1.71 & 0.54 & -2.38 & 0.0087 & 0.999* \\
\hline
\end{tabular}

Note: * Statistically not significant. 
Table 3. Use of ICT in different activities in the city centres.

\begin{tabular}{lccccc}
\hline ICT Use & PI & SD & z-score & z-probability & p-values \\
\hline General socio-economic activities & 4.05 & 0.55 & 1.91 & 0.971 & 0.00 \\
e-Commerce & 3.73 & 0.64 & 1.14 & 0.872 & 0.00 \\
e-Governance/public participation & 2.83 & 0.55 & -0.29 & 0.385 & $0.999 *$ \\
Real-time information display & 1.96 & 0.79 & -1.33 & 0.091 & $0.999 *$ \\
Real-time information access from private mobile devices & 3.92 & 0.62 & 1.47 & 0.929 & 0.000 \\
Real-time monitoring of different social activities and public places & 1.97 & 0.77 & -1.33 & 0.091 & $0.999 *$ \\
Monitoring of criminal and suspicious activities & 2.46 & 0.92 & -0.59 & 0.277 & $0.999 *$ \\
Advertising of the social-cultural activities & 3.17 & 0.67 & 0.27 & 0.606 & 0.00 \\
Promotion of tourism activities & 3.20 & 0.60 & 0.34 & 0.633 & 0.00 \\
Current role of ICT in the city centres & 3.03 & 0.79 & 0.04 & 0.51 & $0.45^{*}$ \\
Perceived role of ICT to improve the city centres & 4.02 & 0.35 & 2.91 & 0.998 & 0.00 \\
\hline
\end{tabular}

Note: * Statistically not significant.

cities, as discussed above, since ICT was not found to be used significantly in a majority of the activities, it would be essential to strengthen, enhance, and promote ICT use in the city centres for their revitalisation.

\subsection{Exploratory Analysis of the Attributes Essential for Revitalising the City Centres}

The exploratory analysis of the attributes that are essential for revitalising the city centres was conducted by using factor analysis. Before the factor analysis, KMO and Bartlett's tests were conducted to check the adequacy of the sample (Table 4). The KMO measure was 0.917, which was more than the minimum recommended value of 0.6. Bartlett's test of sphericity was statistically significant $(p$-value $=0.000,<0.05)$. Thus, the sample was adequate and the factorability of the correlation matrix was supported. Furthermore, the communalities of all the factors shown in Table 5 were greater than 0.6. Also, correlation coefficients between various variables ranged between 0.011 and 0.70 , which implied that the majority of the variables did not show high correlations and, therefore, the chances of over-estimation were limited. However, in cases where a relatively strong correlation $(>0.7)$ between two variables (pairwise) was observed, one of the variables was discarded from the PCA. This indicated that factor analysis was adequate for this study (Tucker \& MacCallum, 1997).
The principal components were extracted and retained by using a scree plot (Figure 1 ), which showed five components with eigenvalues of more than one. Table 6 shows the total variance explained by each component extracted. Component 1 (41.86\%), component 2 (20.81\%), component 3 (11.89\%), component 4 (5.67\%), and component 5 (5.09\%) were predominant, resulting in a cumulative variance percentage of $85.35 \%$ of the influence on the city centres.

Varimax rotation was conducted to interpret the various attributes of the five components that influenced the vitality of the city centres. The results are shown in Table 7. According to the close linkages observed between the various attributes of each component, the five components were labelled as: 1) Enhancing accessibility and safety; 2) Social and community involvement; 3) Human experience; 4) Built-up environment; and 5) Vibrancy.

Each component and the loaded attributes are discussed below.

\subsubsection{Component 1: Enhancing Accessibility and Safety}

Seven attributes were loaded onto this component, including accessibility and pedestrianising (0.955), art and music (0.933), safe (0.919), connected (0.877), walkable (0.874), cosmopolitanism and openness (0.868), and enhancing the local economy and environment

Table 4. KMO and Bartlett's tests.

\begin{tabular}{lcr}
\hline Tests & Parameters & Values \\
\hline KMO measure & Sampling adequacy & 0.917 \\
Bartlett's test of sphericity & Approx. chi-square & $31,862.234$ \\
& Degree of freedom & 300 \\
& Significance & 0.000 \\
\hline
\end{tabular}


Table 5. Communalities.

\begin{tabular}{|c|c|c|}
\hline Attributes & Initial & Extraction \\
\hline Architecture & 1.000 & 0.870 \\
\hline Buzz & 1.000 & 0.960 \\
\hline Diversity & 1.000 & 0.689 \\
\hline Nightlife & 1.000 & 0.842 \\
\hline Public spaces & 1.000 & 0.912 \\
\hline Accessibility and pedestrianising & 1.000 & 0.978 \\
\hline Restaurants and dining & 1.000 & 0.850 \\
\hline Shopping & 1.000 & 0.747 \\
\hline Professional and administrative buildings & 1.000 & 0.894 \\
\hline Quality of buildings & 1.000 & 0.715 \\
\hline Comfortable & 1.000 & 0.946 \\
\hline Safe & 1.000 & 0.889 \\
\hline Vibrant & 1.000 & 0.849 \\
\hline Walkable & 1.000 & 0.806 \\
\hline Cosmopolitanism and openness & 1.000 & 0.805 \\
\hline Social cohesion & 1.000 & 0.889 \\
\hline Art and music & 1.000 & 0.920 \\
\hline Lifestyle & 1.000 & 0.843 \\
\hline Enhancing & 1.000 & 0.789 \\
\hline Connected & 1.000 & 0.816 \\
\hline Diverse & 1.000 & 0.918 \\
\hline Enduring & 1.000 & 0.873 \\
\hline Enriching experience & 1.000 & 0.841 \\
\hline Community involvement and participation & 1.000 & 0.756 \\
\hline Belongingness & 1.000 & 0.941 \\
\hline
\end{tabular}

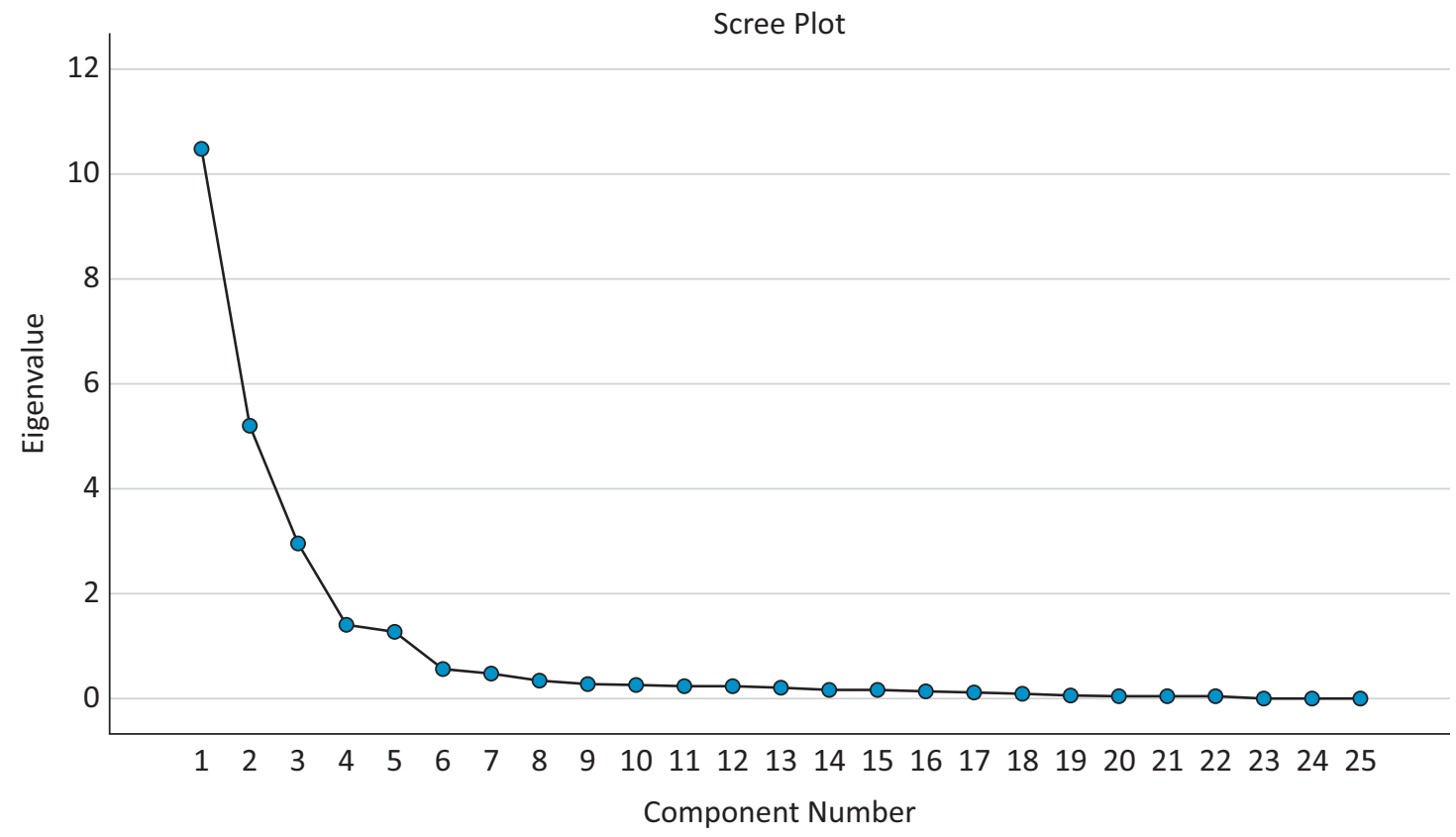

Figure 1. Scree plot showing eigenvalues of the components. 
Table 6. Total variance of the principal components explained.

\begin{tabular}{|c|c|c|c|c|c|c|c|c|c|}
\hline \multirow[b]{2}{*}{ Component } & \multicolumn{3}{|c|}{ Initial Eigenvalues } & \multicolumn{3}{|c|}{$\begin{array}{l}\text { Extraction Sums of } \\
\text { Squared Loadings }\end{array}$} & \multicolumn{3}{|c|}{$\begin{array}{l}\text { Rotation Sums of } \\
\text { Squared Loadings }\end{array}$} \\
\hline & Total & $\begin{array}{c}\% \text { of } \\
\text { Variance }\end{array}$ & $\begin{array}{c}\text { Cumulative } \\
\%\end{array}$ & Total & $\begin{array}{c}\% \text { of } \\
\text { Variance }\end{array}$ & $\begin{array}{c}\text { Cumulative } \\
\%\end{array}$ & Total & $\begin{array}{c}\% \text { of } \\
\text { Variance }\end{array}$ & $\begin{array}{c}\text { Cumulative } \\
\%\end{array}$ \\
\hline 1 & 10.46 & 41.86 & 41.8 & 10.46 & 41.86 & 41.86 & 6.36 & 25.44 & 25.44 \\
\hline 2 & 5.20 & 20.81 & 62.68 & 5.20 & 20.81 & 62.68 & 5.98 & 23.94 & 49.38 \\
\hline 3 & 2.97 & 11.89 & 74.57 & 2.97 & 11.89 & 74.57 & 4.94 & 19.782 & 69.16 \\
\hline 4 & 1.42 & 5.67 & 80.25 & 1.42 & 5.67 & 80.25 & 2.36 & 9.464 & 78.62 \\
\hline 5 & 1.27 & 5.09 & 85.35 & 1.27 & 5.09 & 85.35 & 1.68 & 6.72 & 85.35 \\
\hline
\end{tabular}

(0.858). This component is related to the augmentation of economy and environment, accessibility by different modes of travel, including non-motorised, and freedom from criminal activities. Such attributes have also been confirmed in previous studies (Das, 2016; Gehl, 2016; Vanolo, 2008). This component was the most predominant, with an initial eigen variance of $41.86 \%$ and rotation sums of squared loadings of $25.44 \%$. This indicated that the attributes associated with this component should be prioritised in the revitalisation process. Moreover, since connectivity was one of the major attributes in this component of development, ICT should act as a facilitator and catalyst to reinforce or augment the attributes.

\subsubsection{Component 2: Social and Community Involvement}

Seven items were loaded onto this component, including buzz (0.957), comfortable (0.950), diverse options and experiences (0.938), belongingness $(0.935)$, community involvement and participation (0.856), social cohesion (0.838), and social diversity (0.781). This component is related to comfort, social acceptance, and openness, as well as community engagement and participation in development (Gehl, 2016; Temelová, 2007). Stakeholders, irrespective of any social solidarities, highlighted cohesive behaviour, belongingness, and being empowered to take decisions and carry out development activities in the city centres. This component is

Table 7. Rotated component matrix of the principal components and attributes of central areas.

\begin{tabular}{|c|c|c|c|c|c|}
\hline \multirow[b]{2}{*}{ Attributes } & \multicolumn{5}{|c|}{ Components } \\
\hline & 1 & 2 & 3 & 4 & 5 \\
\hline Accessibility and pedestrianising & 0.955 & 0.066 & 0.235 & 0.080 & 0.017 \\
\hline Art and music & 0.933 & 0.049 & 0.205 & 0.071 & 0.027 \\
\hline Safe & 0.919 & 0.067 & 0.185 & 0.069 & 0.006 \\
\hline Connected & 0.877 & 0.065 & 0.191 & 0.065 & 0.046 \\
\hline Walkable & 0.874 & 0.091 & 0.130 & 0.022 & 0.129 \\
\hline Cosmopolitanism and openness & 0.868 & 0.116 & 0.177 & 0.076 & -0.017 \\
\hline Enhancing local economy and environment & 0.858 & 0.047 & 0.211 & 0.076 & -0.012 \\
\hline Buzz & 0.046 & 0.957 & 0.174 & 0.069 & 0.085 \\
\hline Comfortable & 0.048 & 0.950 & 0.172 & 0.071 & 0.083 \\
\hline Diverse options and experience & 0.043 & 0.938 & 0.164 & 0.068 & 0.073 \\
\hline Belongingness & 0.061 & 0.935 & 0.237 & 0.080 & 0.010 \\
\hline Community involvement and participation & 0.075 & 0.856 & 0.121 & 0.054 & 0.019 \\
\hline Social cohesion & 0.370 & 0.838 & 0.201 & 0.096 & 0.008 \\
\hline Social diversity & 0.064 & 0.781 & 0.054 & 0.007 & 0.267 \\
\hline Enriching experience/feel-good factor & 0.101 & 0.093 & 0.900 & 0.071 & 0.086 \\
\hline Lifestyle & 0.163 & 0.153 & 0.848 & 0.268 & 0.045 \\
\hline Enduring and aesthetically pleasing & 0.356 & 0.189 & 0.836 & 0.103 & 0.002 \\
\hline Public spaces & 0.363 & 0.175 & 0.108 & 0.859 & 0.009 \\
\hline Architecture & 0.180 & 0.130 & 0.304 & 0.853 & 0.029 \\
\hline Professional, commercial, and administrative buildings & 0.165 & 0.113 & 0.403 & 0.831 & 0.025 \\
\hline Residential buildings & 0.030 & 0.006 & 0.174 & 0.827 & -0.014 \\
\hline Vibrant with people around & -0.004 & 0.196 & 0.032 & 0.023 & 0.900 \\
\hline Nightlife & 0.035 & 0.307 & 0.022 & 0.014 & 0.864 \\
\hline Restaurants and dining & 0.229 & 0.159 & 0.024 & 0.355 & 0.804 \\
\hline Shopping & 0.171 & 0.137 & 0.299 & 0.043 & 0.779 \\
\hline
\end{tabular}


aligned with place theory, in which it is argued that empowerment of people and a place should be developed not only by considering spatial or environmental interventions but also by considering public participation (Castree, 2009; Laua \& Lib, 2019). ICT can play a critical role in empowerment and public participation.

\subsubsection{Component 3: Human Experience}

Three factors were loaded onto this component, including enriching experience/feel-good factor (0.900), lifestyle (0.848), and enduring and aesthetically pleasing (0.836). The factors were linked to the perceptions, intangible experiences, and feelings of people which, it has been argued, are essential elements in placemaking, as professed in place theory (Castree, 2009; Laua $\&$ Lib, 2019). Moreover, this component could reinforce Component 2. ICT can be used to create intangible experiences, add perceptions, or bring out feel-good factors through making information available on demand (Laua \& Lib, 2019).

\subsubsection{Component 4: Built-Up Environment}

The built environment is one of the most important components of a place, and the creation of an appropriate built environment assists in creating the importance or the image of a place. Four factors were loaded onto this component, including public spaces (0.859), architecture (0.853), professional, commercial, and administrative buildings (0.831), and residential buildings (0.827). Quality of place is determined by the quality of the public spaces and buildings. The demand for ubiquitous connectivity for performing urban activities, as well as public residential buildings and public places with ICT connectivity are of paramount importance in city centres (Battisti et al., 2019; Corburn \& Cohen, 2012; Zheng et al., 2014). However, the relatively low ranking of this component in this study suggested that improving this component might not be most vital, but it is one of the essential components and should be considered in conjunction with the other ones for the revitalisation of the central areas.

\subsubsection{Component 5: Vibrancy}

A place should be vibrant and lively to attract activities and people; conversely, activities and people make a place vibrant. Four factors were loaded onto this component, including vibrant with people around (0.900), nightlife (0.864), restaurants and dining (0.804), and shopping (0.779). The presence of these attributes was very limited in the city centres of South Africa, as observed during normal hours of the day and almost non-existent in the evening hours. As argued by various scholars, these attributes need to be augmented to bring people and vibrancy back to the places (Gehl, 2016; Laua \& Lib, 2019; Ralph, 2016; Richards \& Palmer, 2010). ICT has the potential to be used to facilitate various activ- ities by making information available often and in realtime for shopping, dining, and recreational activities. ICT can also be used to assist in assessing infrastructure, for example, public transportation, and making it safe (Kingston et al., 2005; Kwon, 2009).

\subsection{Evaluation of ICT-Linked Strategic Measures to Revitalise the City Centres}

To improve the vitality of the city centres based on the augmentation of the five principal components analysed above, it was essential to evaluate what ICT-linked strategies could be implemented to enable the revitalisation of the city centres. For this purpose, six strategies (identified by SID) and the existing status of the city centres were evaluated. Table 8 shows the relative influence of the strategies evaluated, based on their parameter estimates and significance levels.

Five strategies (ICT01-ICT05) were evaluated and compared with the existing status of ICT adoption in the city centres. Four strategies were statistically significant and were likely to assist in revitalisation. These strategies were: network the area with free Wi-Fi hotspots (ICT01), create places to congregate and provide digital screens (ICT02), install surveillance cameras to monitor criminal activities remotely (ICTO5), and install digital maps and signage (ICTO4). Live streaming of national and international sporting or cultural events was not statistically significant and thus could not be linked conclusively to the revitalisation of the city centres.

Networking of the area with free Wi-Fi hotspots was the most significant strategy (ICT01: $\mathrm{B}=3.107$ ) that should be considered in the revitalisation process. This is expected to enhance and provide connectivity for stakeholders and even for people who are without private internet to access real-time information without constraints while in the city centres. This strategy is aligned to Component 1 , enhancing accessibility and safety, which was found to be the most essential component in revitalisation. This strategy is likely to assist in enhancing economic activities and improve accessibility to different means of transportation as well as improving safety through information on various criminal activities (De Filippi et al., 2020; Jeong et al., 2010).

Creating places in which to congregate and providing digital screens (ICTO2: $\mathrm{B}=2.265$ ) was the second most significant strategy. Implementing this strategy can enable the transmission of information as well as the broadcasting of different socio-cultural, entertainment, and sporting events. Consequently, implementing the strategy can result in the creation of a vibrant environment, which can attract people to such places (Gehl, 2016; Laua \& Lib, 2019; Ralph, 2016). Moreover, this might help to enhance interaction among people or communities, which might increase community involvement and participation in the activities in city centres.

The installation of surveillance cameras to monitor criminal activities remotely (ICT05: $B=1.843$ ) was the 
Table 8. Influence of ICT-related strategies in revitalising the city centres.

\begin{tabular}{|c|c|c|c|c|c|c|c|}
\hline SID & Strategies & Estimate (B) & $\operatorname{EXP}(B)$ & Wald & Significance & $\begin{array}{l}\text { Upper } \\
\text { Bound }\end{array}$ & $\begin{array}{l}\text { Lower } \\
\text { Bound }\end{array}$ \\
\hline ICT01 & $\begin{array}{l}\text { Network the area with free Wi-Fi } \\
\text { hotspots }\end{array}$ & 3.107 & 22.35 & 25.379 & 0.000 & 1.898 & 4.315 \\
\hline ICT02 & $\begin{array}{l}\text { Create places to congregate and } \\
\text { provide digital screens }\end{array}$ & 2.265 & 9.63 & 18.131 & 0.000 & 1.222 & 3.307 \\
\hline ICT03 & $\begin{array}{l}\text { Live-stream national and international } \\
\text { sporting activities }\end{array}$ & 0.795 & 2.21 & 2.674 & $0.102 *$ & -0.158 & 1.747 \\
\hline ICT04 & Install digital maps and signage & 1.402 & 4.063 & 7.577 & 0.006 & 0.404 & 2.400 \\
\hline ICT05 & $\begin{array}{l}\text { Install surveillance cameras to } \\
\text { monitor criminal activities remotely }\end{array}$ & 1.843 & 6.31 & 12.370 & 0.000 & 0.816 & 2.870 \\
\hline ICTOO & Current status of ICT adoption & 0 & 1 & & & & \\
\hline
\end{tabular}

Note: * Statistically not significant.

third most significant strategy that should be considered for revitalisation. It has been alleged that many criminal activities take place in South African city centres and people hesitate to visit them out of fear. Remotely monitored surveillance cameras can make it possible to detect criminal activities and assist in arresting people involved in crime. Moreover, the strategy can enable law enforcement departments to detect suspicious activities or people and prevent the occurrence of any untoward or criminal incidents. Furthermore, this is expected to boost the confidence of people and alleviate their fear of visiting the city centres. On the other hand, it will discourage the criminals from being involved in criminal activities for fear of being caught. Therefore, such a strategy could be an essential element in revitalising the city centres, which has scarcely been considered in any urban renewal or redevelopment process. However, this measure must be taken without creating an impression of a heavily policed or secured area and without compromising people's privacy (Wolfe, 2020).

The fourth most significant strategy that should be considered is the installation of digital maps and signage (ICT03: $\mathrm{B}=1.402$ ). Although this strategy was perceived to have relatively less impact than the other three strategies, digital maps and signage are one of the most important requirements in important places. Implementing this strategy would assist in orienting people to the built environment or area in relation to a destination (White, 2014). It will provide directions and information about the location of various activities to visitors, who might not be able to access such information from their mobile devices. This would also improve accessibility to different places, activities, and modes of transportation in the city centres.

\section{Conclusions}

Most efforts to upgrade the built environment are made through spatial and physical interventions, the major- ity of which achieve some cosmetic changes, but the challenge of continual degeneration remains the same. In this study, the argument has been made to revitalise city centres by integrating ICT into the socio-economic and cultural fabric of cities.

Five components and their attributes were shown to be significant in revitalising city centres. These were: enhancing accessibility and safety, social and community involvement, human experience, built-up environment, and vibrancy. Thus, while improving the spatial built environment is important, revitalisation demands more than that. The aims of transformation should be to make the city centres accessible and safe, to enhance economic opportunities, to build on social and community involvement, to offer enriching human experiences, and to create vibrancy by attracting people and activities. It has been argued that ICT can be used as an enabler or facilitator to attain the above-mentioned transformation. However, it was found that, although accessibility of ICT in the city centres does exist to a certain extent, it needs significant reinforcement. Furthermore, although ICT is being used in different activities of city centres to a certain extent, such as in general socio-economic activities and for promotional and advertising purposes, it is not used significantly in many essential activities, such as monitoring crimes, public participation in governance systems, and displaying real-time information in public places. It is perceived that ICT could be deployed to contribute significantly to the creation of vibrant city centres if appropriately augmented.

Four ICT-linked strategies were found to be significant in assisting in this transformation. ICT networking with free Wi-Fi hotspots is expected to enhance economic activities and accessibility. Creating places in which to congregate and providing digital screens might assist in broadcasting socio-cultural and entertainment events, which could attract people and improve social interaction. Moreover, social interaction combined with the availability of free Wi-Fi will empower people to 
participate in the decision-making and development of city centres. Installing surveillance cameras and remote monitoring of activities, without compromising the privacy of people and creating an impression of a policing atmosphere, is likely to help in discouraging criminal activities as well as dispelling fear by making city centres safe to visit. Installing digital maps and signage would reinforce accessibility by different modes of transportation. Thus, the combined effect of these ICT strategies is expected to make city centres more empowering, safer, and more vibrant.

\section{Acknowledgments}

The author acknowledges the support of the National Research Foundation (NRF), South Africa, for this research (Grant No. 106023, 15-12-2016). The author thanks the people who have assisted in data collection. The author also appreciates the experts who have provided their valuable opinions and suggestions.

\section{Conflict of Interests}

The author declares no conflict of interests.

\section{References}

Alexander, A., Teller, C., \& Wood, S. (2020). Augmenting the urban place brand-On the relationship between markets and town and city centres. Journal of Business Research, 116, 642-654. https://doi.org/ 10.1016/j.jbusres.2019.02.013

Alghamdi, S. A., \& Al-Harigi, F. (2015). Rethinking image of the city in the Information Age. Procedia Computer Science, 65, 734-743.

Al-Kodmany, K., \& Ali, M. M. (2012). Skyscrapers and placemaking: Supporting local culture and identity. Archnet-IJAR, 6(2), 46-67.

Battisti, A., Barnocchi, A., \& lorio, S. (2019). Urban regeneration process: The case of a residential complex in a suburb of Rome, Italy. Sustainability, 11(21), Article 6122. https://doi.org/10.3390/su11216122

Castells, M. (1996). The rise of the network society. Wiley. Castree, N. (2009). Place: Connections and boundaries in an interdependent world. In N. Clifford, S. Holloway, S. P. Rice, \& G. Valentine (Eds.), Key concepts in geography (2nd ed., pp. 153-172). SAGE.

Corburn, J., \& Cohen, A. K. (2012). Why we need urban health equity indicators: Integrating science, policy, and community. PLoS Medicine, 9(8), Article e1001285. https://doi.org/10.1371/journal.pmed. 1001285

Das, D. K. (2016). Engendering creative city image by using information communication technology in developing countries. Urban Planning, 1(3), 1-12. https://doi.org/10.17645/up.v1i3.686

De Filippi, F., \& Balbo, R. (2011). Planning for real: ICT as a tool in urban regeneration. The Built \& Human
Environment Review, 4(1), 67-73.

De Filippi, F., Coscia, C., \& Guido, R. (2020). Digital platforms for enhancing participatory design and urban regeneration: A case study in Turin (Italy). In C. N. Silva (Ed.), Citizen-responsive urban e-planning: Recent developments and critical perspectives (pp. 54-82). IGI Global.

Fernandez-Maldonado, A. M. (2012). ICT and spatial planning in European cities: Reviewing the new charter of Athens. Built Environment, 38(4), 469-483. http://www.jstor.org/stable/23289949

Gehl, J. (2016). Creating places for people: An urban design protocol for Australian cities. Urban Design Protocol. https://urbandesign.org.au/content/ uploads/2015/08/INFRA1219_MCU_R_SQUARE_ URBAN_PROTOCOLS_1111_WEB_FA2.pdf

Hsu, C.-C., \& Sandford, B. A. (2007). The Delphi technique: Making sense of consensus. Practical Assessment, Research, and Evaluation, 12, Article 10. https://doi.org/10.7275/pdz9-th90

Jeong, E., Shim, I. K., \& Wilson, M. I. (2010). Urban regeneration, retail development and the role of information and communication technologies: Scientific outlook. NETCOM, 24(1/2), 133-146. https://doi.org/ 10.4000/netcom.481

Jolliffe, I. T., \& Cadima, J. (2016). Principal component analysis: A review and recent developments. Philosophical Transactions of the Royal Society A: Mathematical, Physical and Engineering Sciences, 374(2065), Article 20150202. https://doi.org/ 10.1098/rsta.2015.0202

Jones, C., \& Livingstone, N. (2018). The "online high street" or the high street online? The implications for the urban retail hierarchy. The International Review of Retail, Distribution and Consumer Research, 28, 47-63. https://doi.org/10.1080/09593969. 2017.1393441

Kingston, R., Babicki, D., \& Ravetz, J. (2005). Urban regeneration in the intelligent city. In Proceedings of the 9th International Conference on Computers in Urban Planning and Urban, Management (Paper 30). University College London. https://www.researchgate. net/publication/228659685_Urban_regeneration_ in_the_intelligent_city

Kwon, Y. S. (2009). From penetration to information service accessibility and usability: Wi-Fi hotspots in 100 U.S. cities. NAF_BBA_Workshop.

Laua, C., \& Lib, Y. (2019). Analyzing the effects of an urban food festival: A place theory approach. Annals of Tourism Research, 74, 43-55.

Lee, G. K. L., \& Chan, E. H. W. (2008). The analytic hierarchy process (AHP) approach for assessment of urban renewal proposals. Social Indicators Research, 89(1), 155-168.

Lepy, E. (2008). Information and communication technologies, a tool for risk prevention and accident management on sea ice: The case of the Bay of Bothnia (Baltic Sea). NETCOM, 22(3/4), 255-264. 
Liggett, D., McIntosh, A., Thompson, A., Gilbert, N., \& Storey, B. (2011). From frozen continent to tourism hotspot? Five decades of Antarctic tourism development and management, and a glimpse into the future. Tourism Management, 32, 357-360.

Little, D. (2013, September 15). The global city: Saskia Sassen. Understanding Society. https:// understandingsociety.blogspot.com/2013/09/theglobal-city-saskia-sassen.html

McDonald, R., \& Swinney, P. (2019). City centres: Past, present and future. Their evolving role in the national economy. Centre for Cities. https://www.centre forcities.org/wp-content/uploads/2019/02/201902-13-City-centres-past-present-and-future.pdf

Mitchell, W. J., \& Casalegno, F. (2008). Connected sustainable cities. MIT Mobile Experience Lab Publishing.

Nkosi, T. (2018). Smarter cities of the future. White paper: ICT innovation and adaptation. Boffin \& Fundi. http://boffinfundi.co.za/wp-content/uploads/2018/ 01/JN4084-ICT-White-Paper-2017.pdf

Powe, N., \& Hart, T. (2008). Market towns: Understanding and maintaining functionality. The Town Planning Review, 79, 347-370. https://doi.org/10.3828/ tpr.79.4.2

Pratt, A. C. (2008). Creative cities: The cultural industries and the creative class. Geografiska Annaler: Series B, Human Geography, 90(2), 107-117. https://doi.org/ 10.1111/j.1468-0467.2008.00281.x

Pred, A. (1984). Place as historically contingent process: Structuration and the time-geography of becoming places. Annals of the Association of American Geographers, 74(2), 279-297.

Ralph, E. C. (1976). Place and placelessness. Pion.

Ralph, E. C. (2016). Afterword. In R. Freestone \& E. Liu (Eds.), Place and placelessness revisited (pp. 269-271). Routledge.

Richards, G., \& Palmer, R. (2010). Eventful cities: Cultural management and urban revitalisation. ButterworthHeinemann.

Rowe, G., \& Wright, G. (2001). Expert opinions in forecasting: The role of the Delphi technique. In J. S. Armstrong (Ed.), Principles of forecasting: A handbook for researchers and practitioners (pp. 125-144). Springer.

Sassen, S. (1996). Cities and communities in the global economy: Rethinking our concepts. American Behavioural Scientist, 39(5), 629-639.

Steyn, G. (2012). Le Corbusier's town-planning ideas and the ideas of history. SAJAH, 27(1), 83-106.

Storper, M. (2010). Why does a city grow? Specialisation, human capital or institutions? Urban Studies, 47(10), 2027-2050.

Strydom, W., Puren, K., \& Drewes, E. (2018). Exploring theoretical trends in placemaking: Towards new perspectives in spatial planning. Journal of Place Man- agement and Development, 11(2), 65-180. https:// doi.org/10.1108/JPMD-11-2017-0113

Temelová, J. (2007). Flagship developments and the physical upgrading of the post-socialist inner city: The golden angel project in prague. Geografiska Annaler: Series B, Human Geography, 89(2), 169-181. https://doi.org/10.1111/j.1468-0467.2007.00246.x

Todes, A. (2011). Reinventing planning: Critical reflections. Urban Forum, 22(2), 115-133. https://doi.org/ 10.1007/s12132-011-9109-x

Tucker, L. R., \& MacCallum, R. C. (1997). Exploratory factor analysis. UCLA. https://labs.dgsom.ucla.edu/ hays/files/view/docs/factor.pdf

van den Berg, L., \& van Winden, W. (2002). Should cities help their citizens to adopt ICTs? On ICT-adoption policies in European cities. Environment and Planning C: Government and Policy, 20(2), 263-279. https: //doi.org/10.1068/c0068

Vanolo, A. (2008). The image of the creative city: Some reflections on urban branding in Turin. Cities, 25(6), 370-382. https://doi.org/10.1016/j.cities.2008.08. 001

Velliangiri, S., Alagumuthukrishnan, S., \& Thankumar Joseph, S. I. (2019). A review of dimensionality reduction techniques for efficient computation. Procedia Computer Science, 165, 104-111. https://doi.org/10.1016/j.procs.2020.01.079

Wang, H., Shen, Q., Tang, B.-S., Lu, C., Peng, Y., \& Tang, L. (2014). A framework of decision-making factors and supporting information for facilitating sustainable site planning in urban renewal projects. Cities, 40, 44-55.

White, R. W. (2014). Moving forward: Opportunities for Vancouver's digital wayfinding map. City of Vancouver Engineering Services, Streets Activities. https://sustain.ubc.ca/sites/default/files/201414_Vancouver\%27s\%20Digital\%20Wayfinding\% 20Map_White.pdf

Williams, R. A., \& Quiroz, C. (2020). Ordinal regression models. In P. Atkinson, S. Delamont, A. Cernat, J. W. Sakshaug, \& R. A. Williams (Eds.), SAGE research methods foundations (pp. 1-25). SAGE. https:// www.doi.org/10.4135/9781526421036885901

Wolfe, C. (2020, July 13). Balancing privacy concerns with video monitoring capabilities. SDM. https:// www.sdmmag.com/articles/98278-balancingprivacy-concerns-with-video-monitoring-capabilities

Wrigley, N., \& Lambiri, D. (2014). High street performance and evolution: $A$ brief guide to the evidence. Economic \& Social Research Council/University of Southampton. https://doi.org/10.13140/2.1.3587. 9041

Zheng, H., Shen, G. Q., \& Wang, H. (2014). A review of recent studies on sustainable urban renewal. Habitat International, 41, 272-279. 


\section{About the Author}



Dillip Kumar Das (Prof.) has a PhD in Urban and Regional Planning with a civil engineering and city planning background. Currently, he is engaged in teaching, research, and community engagement activities in the University of KwaZulu-Natal, South Africa. His research and consulting interests under sustainable urban and regional development include systems analysis, system dynamics modelling, infrastructure planning and management, smart cities, and transportation planning. He has co-authored two books as the lead author and published several peer-reviewed research articles. 